\title{
Discoid Lupus Erythematosus and Vitiligo
}

\author{
Mehdi Khallaayoune*, Siham Belmourida, Fatima Ezzahra Elgaitibi, Nadia Ismaili, Mariame Meziane, Karima \\ Senouci and Leila Benzekri
}

Department of Dermatology, Ibn Sina University Hospital, Mohammed V University, Morocco

Submission: March 04, 2021; Published: March 29, 2021

*Corresponding author: Mehdi Khallaayoune, Department of Dermatology, Ibn Sina University Hospital, Mohammed V University, Morocco

Abstract

Patients with autoimmune conditions are more likely than others to develop additional inflammatory or disimmunity affections. Both discoid lupus eryhtematosus (DLE) and vitiligo may associate with various other autoimmune disorders. Coexistence of DLE and vitiligo in the same patient have also been reported. Understanding of this rare pathological association remains unclear and diagnosis may appear challenging as depigmentation manifests in both diseases. Through the clinical, histological and immunochemical findings of a 38-year-old patient with simultaneous DLE and vitiligo, we discuss physiopathology, diagnosis and management of this unlikely association.

Keywords: Discoid lupus erythematosus; Vitiligo; E-cadherins; Melanocytorrhagy

\section{Introduction}

A 38 year old patient presented for hypochromic pruritic lesions progressing for 6 months. Physical examination found hypochromic erythematous scaly atrophic plaques on the nose, ears, neckline, hands and feet with lips depigmentation (Figure 1). Skin biopsy revealed epidermal atrophy with orthokeratosis, basal vacuolization and perivascular lymphoplasma cells infiltrate. Direct immunofluorescence was positive for lupus band. Based on these findings a first diagnosis of DLE was retained. Assessment for systemic involvement was negative. Lips depigmentation, perifollicular repigmentation areas and non-atrophic "vitiligo-like" lesions with Koebner phenomenon on toes and hands raised suspicion for an associated vitiligo. Immunochemical analysis was performed on "vitiligo-like" lesions showing no lupus stigmata with complete loss of melanocytes (HMB45, Melan A, PS100 negative) and E cadherins consistent with a vitiligo (Figure 2). Photoprotection, hydroxychloroquine $200 \mathrm{mg}$ twice a day and tacrolimus $0,1 \%$ were implemented with a significant improvement on itching, erythema and plaques size. Oldest articles mainly refer to the differential diagnosis between DLE and vitiligo lesions more than the possible association. There is poor evidence of higher risk of DLE in vitiligo patients. However increasing reports of well documented cases have raised suspicion for a common genetic predisposition. The identification of the
SLEV 1 gene mutations on chromosome 17 p 13 in patients with systemic lupus and vitiligo provided strong arguments supporting a genetic relationship between both diseases [1].

UV light may also play a role inducing lupus on preexisting hypochromic vitiligo lesions [2,3]. On the other hand overexpression of HSP 70 protein found in DLE and vitiligo skin is thought stimulating the development of inflammatory lesions in both diseases [4]. E cadherin deficiency has been related to melanocytorrhagy in vitiligo [5]. This phenomenon is a nonautoimmune loss of melanocytes mechanism different from autoimmune vitiligo. Our patient demonstrated E-cadherin deficiency supporting existence of a transepidermal loss of melanocyte phenomenon. Lupus inflammatory lesions and itching could have favoured melanocytorhagia. Taken together all these hypothesis suggest that association between DLE and vitiligo might not be a simple random. Diagnosis should be suspected when patients with DLE display Koebner phenomenon and achromic or hypochromic plaques without skin atrophy. Biopsy of those lesions may then be the clue for the diagnosis. Early recognition is imperative as the presence of one disorder may affect the therapy of the second. Both conditions should be taken into account when choosing treatment. Phototherapy is not allowed in DLE whereas it is an excellent option for labial involvement in 


\section{Juniper Online Journal of Dermatology \& Cosmetics}

vitiligo [6]. Tacrolimus is effective in both DLE and vitiligo and should be always proposed. Our patient was put on tacrolimus and hdroxychloroquine with favourable outcomes. Emollients and barrier creams may also be useful in areas of trauma and friction where Koebner's phenomenon is likely to occur.

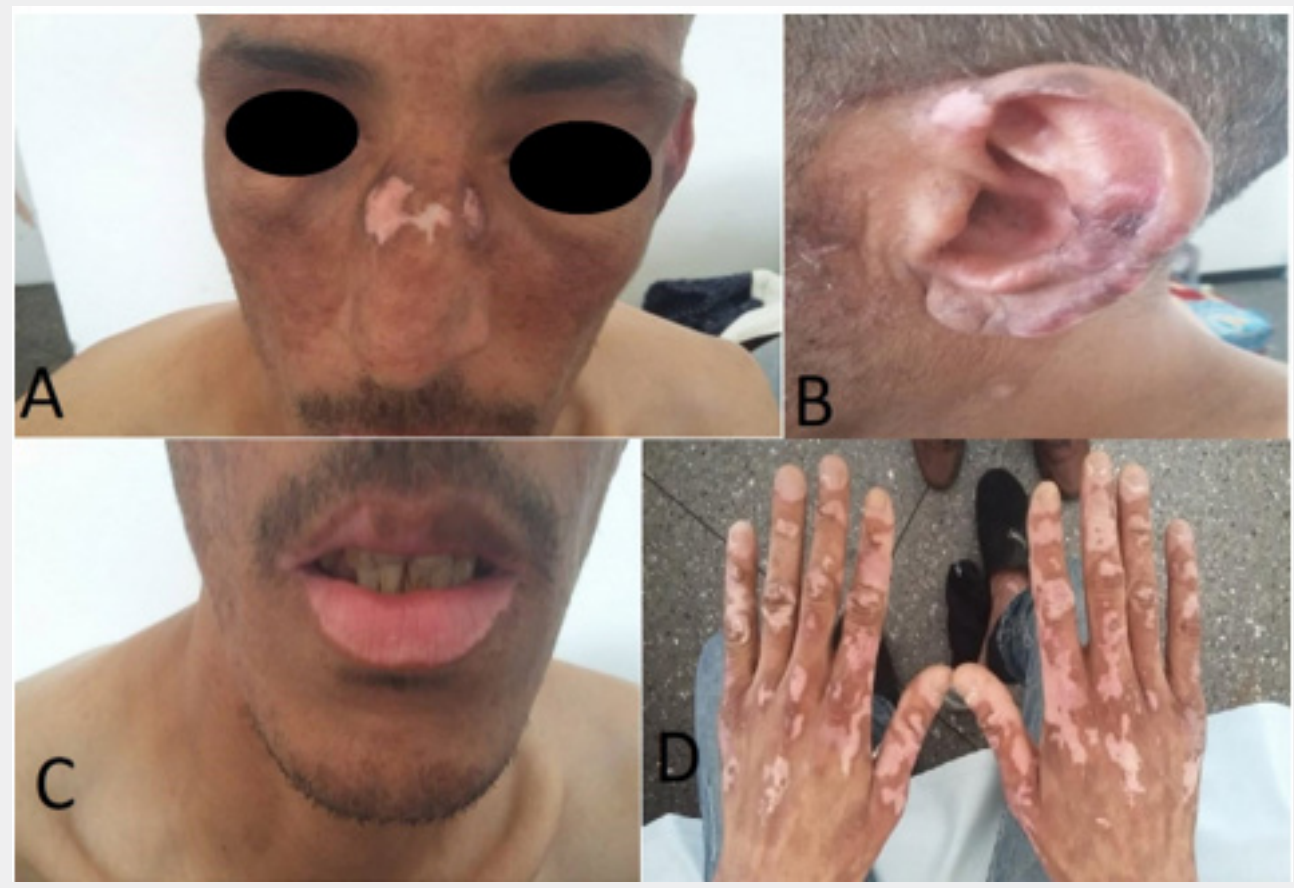

Figure 1: (A) Hypochromic atrophic plaques on the nose and (B) ears, (C) Lips depigmentation and (D) Vitiligo-like lesion on hands.

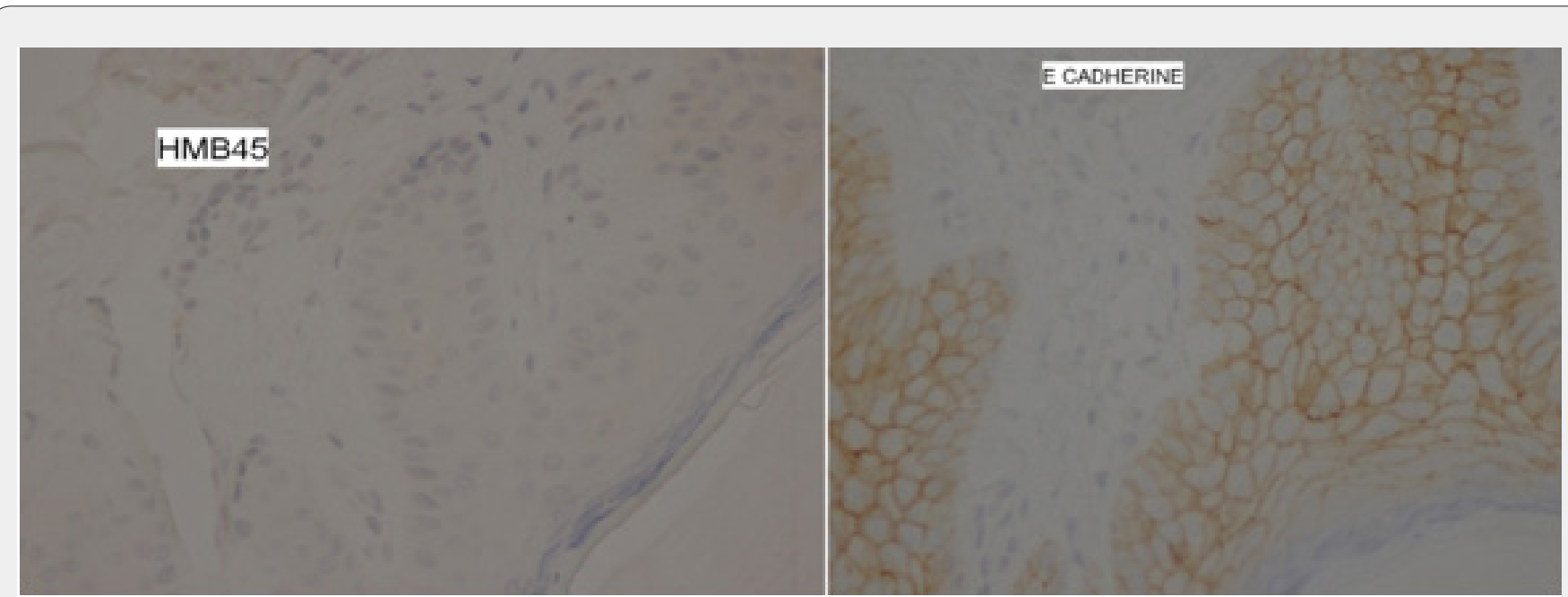

Figure 2: HMB45 negative staining with loss of E-cadherins.

\section{References}

1. Kovacs SO (1998) Vitiligo J Am Acad Dermatol 38(5 Pt 1): 647-666.

2. Callen JP (1984) Discoid lupus erythematosus in a patient with vitiligo and autoimmune thyroiditis. Int J Dermatol 23(3): 203-204.

3. Nath SK, Kelly JA, Namjou B, Lam T, Bruner GR, et al. (2001) Evidence for a susceptibility gene, SLEV1, on chromosome $17 \mathrm{p} 13$ in families with vitiligo related systemic lupus erythematosus. Am J Hum Genet 69(6): 1401-1406.

4. Jacquemin C, Rambert J, Guillet S, Thiolat D, Boukhedouni N, et al. (2017) HSP70 potentiates interferon alpha production by plasmacytoid dendritic cells: relevance for cutaneous lupus and vitiligo pathogenesis. Br J Dermatol 177(5): 1367-1375. 
5. Cario AM, Pain C, Gauthier Y, Taïeb A (2007) The melanocytorrhagic hypothesis of vitiligo tested on pigmented, stressed, reconstructed epidermis. Pigment Cell Res 20(5): 385-93.
6. Sharma S, Sarkar R, Garg VK, Bansal S (2013) Coexistence of liptip vitiligo and disseminated discoid lupus erythematosus with hypothyroidism: Need for careful therapeutic approach. Indian Dermatol Online J 4(2): 112-4.
This work is licensed under Creative Commons Attribution 4.0 License DOI: $10.19080 / J O J D C .2021 .04 .555626$

\section{Your next submission with Juniper Publishers will reach you the below assets}

- Quality Editorial service

- Swift Peer Review

- Reprints availability

- E-prints Service

- Manuscript Podcast for convenient understanding

- Global attainment for your research

- Manuscript accessibility in different formats ( Pdf, E-pub, Full Text, Audio)

- Unceasing customer service

Track the below URL for one-step submission

https://juniperpublishers.com/online-submission.php 